\title{
Performance of dispersion-corrected density functional theory for thermochemistry and non-covalent interactions
}

\author{
Waldemar Hujo ${ }^{*}$, Stefan Grimme \\ From 7th German Conference on Chemoinformatics: 25 ClC-Workshop \\ Goslar, Germany. 6-8 November 2011
}

The accuracy of non-local van der Waals density functional [1] is tested for the thermochemical properties of $1200+$ atoms and molecules in the GMTKN30 database. Five (hybrid)GGA functionals are augmented by the non-local (NL) part of the VV10 functional. The widely used atom-pair wise dispersion correction DFT-D3 [2] is considered for comparison. The addition of the NL dispersion energy definitely improves the results of all tested short-range functionals. Based on little empiricism and basic physical insight, DFT-NL can be recommended as robust electronic structure method.

For more detailed insight into non-covalent bonding, potential energy curves [3] for five complexes with weak to medium strong hydrogen bonds have been computed with dispersion corrected DFT methods VV10, DFT-D3 and vdW-DF2 [4]. All dispersion corrected methods perform reasonably well for these hydrogen bonds. For the fluorinated complexes, the VV10 method gives remarkably good results. The vdW-DF2 method yields good interaction energies similar to the other methods, but fails to provide accurate equilibrium separations. For large-scale applications we can recommend DFT-D3 based structure optimizations with subsequent checking of interaction energies by single-point VV10 computations.

Published: 1 May 2012

\section{References}

1. Vydrov OA, van Voorhis T: J Chem Phys 2010, 133:244103.

2. Grimme S, Antony J, Ehrlich S, Krieg H: J Chem Phys 2010, 132:154104.

Mulliken Center for Theoretical Chemistry, Institute for Physical and Theoretical Chemistry, University of Bonn, Beringstr. 4, D-53115 Bonn, Germany

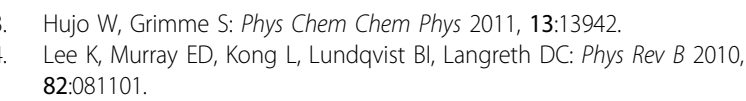

doi:10.1186/1758-2946-4-S1-P56

Cite this article as: Hujo and Grimme: Performance of dispersioncorrected density functional theory for thermochemistry and non-covalent interactions. Journal of Cheminformatics 2012 4(Suppl 1):P56.
Publish with ChemistryCentral and every scientist can read your work free of charge

"Open access provides opportunities to our colleagues in other parts of the globe, by allowing anyone to view the content free of charge."

W. Jeffery Hurst, The Hershey Company.

- available free of charge to the entire scientific community

- peer reviewed and published immediately upon acceptance

- cited in PubMed and archived on PubMed Central

- yours - you keep the copyright

Submit your manuscript here:

http://www.chemistrycentral.com/manuscript/

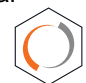

ChemistryCentral

(c) 2012 Hujo and Grimme; licensee BioMed Central Ltd. This is an Open Access article distributed under the terms of the Creative Commons Attribution License (http://creativecommons.org/licenses/by/2.0), which permits unrestricted use, distribution, and reproduction in any medium, provided the original work is properly cited. 